\title{
Humanización de los cuidados intensivos durante la pandemia por COVID-19. ¿Una oportunidad para reivindicar la atención?
}

\author{
Humanization of intensive care during the COVID-19 \\ pandemic. An opportunity to revindicate care?
}

\author{
Miguel Ángel Martínez Camacho, ${ }^{*}$ Alberto Gómez González, ${ }^{*}$ ₹ Robert Alexander Jones Baro* \\ Citar como: Martínez CMÁ, Gómez GA, Jones BRA. Humanización de los cuidados intensivos durante la pandemia por COVID-19. ¿Una \\ oportunidad para reivindicar la atención? Acta Med Grupo Angeles. 2021; 19 (2): 302-303. https://dx.doi.org/10.35366/100464
}

La pandemia generada por la infección de SARS-CoV-2 ha golpeado a todo el mundo durante poco más de un año. En este tiempo la evidencia sobre el manejo, las precauciones y la forma de prevención ha ido cambiando según se obtiene la mejor evidencia disponible. Una de las medidas más difundidas para los profesionales de la salud es el uso adecuado del equipo de protección personal (EPP); sin embargo, las recomendaciones en cuanto a su uso también han ido cambiando conforme se investiga más este virus. Un artículo reciente menciona que la vía de transmisión principal es respiratoria, quedando con poca evidencia la transmisión por otros medios. ${ }^{1}$ Esto abre la oportunidad de reducir la cantidad de equipo que los profesionales necesitan, enfatizando la protección respiratoria, ocular, lavado de manos, uso de guantes y medidas de aislamiento estándar.

Por otro lado, un reciente metaanálisis menciona que los pacientes infectados por SARS-CoV-2 que tienen más de 10 días desde el inicio de los síntomas no poseen la capacidad de contagiar a otras personas, este periodo puede prolongarse en casos graves hasta 15 días. $^{2}$ Teniendo en cuenta que los pacientes que ingresan a una Unidad de Cuidados Intensivos ( $\mathrm{UCl}$ ) debido al grado de severidad de la enfermedad de COVID-19 suelen permanecer más tiempo hospitalizados, ¿tiene entonces sentido tenerlos aislados por tanto tiempo?, ¿las precauciones que utilizamos se basan realmente en evidencia o mejor dicho, en opiniones? En esta época de pandemia hemos llevado a los extremos las medidas de protección, lo cual estaba justificado al inicio debido a que nos encontrábamos ante una situación desconocida, pero ahora a más de un año y con más información, ¿qué podemos cambiar en la atención?

Como se mencionó anteriormente uno de los problemas principales desde el aspecto de la humanización ha sido el aislamiento por tiempos prolongados de los pacientes con COVID-19. En la actualidad existe la implementación de videollamadas por medio de dispositivos móviles en algunos centros hospitalarios, lo cual se debería volver un estándar de atención en el manejo de estos pacientes. Esta opción es la más viable cuando el paciente aún es potencialmente contagioso y es capaz de cooperar de manera activa. De manera adicional se puede implementar buzón de cartas, diario de la $\mathrm{UCl}$ y material audiovisual elaborado por la familia.

El proceso de internamiento en una $\mathrm{UCl}$, la hospitalización prolongada, periodos largos de sedación y ventilación en general pueden propiciar efectos adversos como el delirum, el cual se ha reportado con una alta incidencia en los pacientes con COVID-19 de hasta 54.9\%. ${ }^{3,4}$ Existen medidas no farmacológicas como el manejo de la sedación-analgesia, respetar el ciclo de sueño-vigilia, evitar dispositivos de restricción de movimiento y la visita de la familia o amigos, siendo esta última la medida reportada con mayor impacto en COVID-19. ${ }^{3}$ Existe el paquete

\footnotetext{
* Servicio de Fisioterapia de la Terapia Intensiva Respiratoria Reconvertida.

‡ Servicio de Fisioterapia de Medicina Interna, Torre Quirúrgica.

Hospital General de México “Dr. Eduardo Liceaga”. Ciudad de México, México.
}

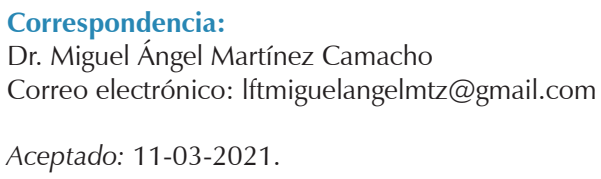

Aceptado: 11-03-2021. 
"ABCDEFGH" para liberar al paciente de la enfermedad crítica y prevenir el síndrome post-cuidados intensivos, el cual ya se aplica a los pacientes con COVID-19 en algunas partes del mundo, la letra " $F$ " hace referencia al empoderamiento familiar, por tanto, en los pacientes con una estancia prolongada se vuelve razonable el acompañamiento de la familia en la $\mathrm{UCl} .^{4-6}$ Cabe aclarar que no en todos los casos será posible, sobre todo en los estadios iniciales de la enfermedad donde el riesgo de contagio es muy alto; sin embargo, en semanas posteriores cuando el paciente deja de ser potencialmente contagioso se debe considerar esta posibilidad. Una alternativa es la división de los pacientes según el riesgo de contagio que representan en diferentes salas o pabellones del hospital, teniendo separados a los pacientes con "alto riesgo" y "bajo riesgo". Se vuelve crucial la educación de la familia en las medidas estándar de protección personal como se haría en cualquier paciente crítico.

El aislamiento prolongado de estos pacientes parece ya no estar justificado. La medicina crítica actual necesita integrar acciones en las cuales la familia y los seres queridos del paciente sean una pieza clave en los cuidados del enfermo crítico. La pandemia actual no es una justificación para deshumanizar la atención en salud. Si bien la humanización de los servicios va más allá de las visitas de la familia, esto parece ser lo más complicado de cumplir en la actualidad.

\section{REFERENCIAS}

1. Meyerowitz EA, Richterman A, Gandhi RT, Sax PE. Transmission of SARS-CoV-2: a review of viral, host, and environmental factors. Ann Intern Med. 2021; 174 (1): 69-79.

2. Cevik M, Tate M, Lloyd O, Maraolo AE, Schafers J, Ho A. SARSCoV-2, SARS-CoV, and MERS-CoV viral load dynamics, duration of viral shedding, and infectiousness: a systematic review and meta-analysis. Lancet Microbe. 2021; 2 (1): e13-e22. doi: 10.1016/ S2666-5247(20)30172-5.

3. Pun BT, Badenes R, Heras La Calle G, Orun OM, Chen W, Raman R et al. Prevalence and risk factors for delirium in critically ill patients with COVID-19 (COVID-D): a multicentre cohort study. Lancet Respir Med [Internet]. 2021; 9 (3): 239-250. Available in: https://linkinghub. elsevier.com/retrieve/pii/S2213-2600(20)30552-X

4. Kotfis K, Williams Roberson S, Wilson JE, Dabrowski W, Pun BT, Ely EW. COVID-19: ICU delirium management during SARS-CoV-2 pandemic. Crit Care. 2020; 24 (1): 176.

5. Martínez-Camacho MA, Jones-Baro RA, Gómez-González A, Morales-Hernández D, Perez-Nieto OR, Zamarron-Lopez El. Postintensive care syndrome - A necessary harm in the critically ill? ICU Management \& Practice. 2020; 20 (4): 300-304.

6. Devlin JW, O'Neal HR Jr, Thomas C, Barnes Daly MA, Stollings JL, Janz DR et al. Strategies to optimize ICU liberation (A to F) bundle performance in critically ill adults with Coronavirus Disease 2019. Crit Care Explor. 2020; 2 (6): e0139. 